\title{
Professional communication tools in Higher Education: a case study in implementing slack in the curriculum.
}

MENZIES, R. and ZARB, M.

(C) 2020 IEEE. Personal use of this material is permitted. Permission from IEEE must be obtained for all other uses, in any current or future media, including reprinting/republishing this material for advertising or promotional purposes, creating new collective works, for resale or redistribution to servers or lists, or reuse of any copyrighted component of this work in other works. 


\section{Professional Communication Tools in Higher Education: A Case Study in Implementing Slack in the Curriculum}

\author{
Rachel Menzies \\ Computing \\ University of Dundee \\ Dundee, UK \\ r.menzies@dundee.ac.uk
}

\author{
Mark Zarb \\ School of Computing \\ Robert Gordon University \\ Aberdeen, UK \\ m.zarb@rgu.ac.uk
}

\begin{abstract}
This Innovative Practice Full Paper presents a study which considers the implications of embedding professional communication tools within the computing curriculum. Computing students are comfortable using various communication tools such as social media applications in their personal lives, but are rarely trained or monitored when transitioning to using these tools professionally. This is despite the fact that these tools, such as Slack, Jabber and Microsoft Teams are rapidly becoming an expected staple of their professional toolkit. 243 students were invited to use Slack as their primary communication mechanism for set taught modules with staff and their fellow students across two institutions in Scotland. This allowed for an understanding to be developed of computing students' attitudes and experiences when using these communication tools, as well as a reflection on staff experiences. A number of recommendations are made for the inclusion of these tools within computing in Higher Education curricula.
\end{abstract}

Index Terms-professional communication tools, Slack, community of practice

\section{INTRODUCTION}

The use of enterprise social networks, and associated communication tools (e.g. Slack, Jabber, Microsoft Teams), are gaining popularity in the workplace and can be beneficial for forming a professional community of practice. These tools are used within the workplace to manage day-to-day activities, arrange coding resources and aid communication between colleagues. Whilst the majority of students are comfortable using similar solutions for their personal and social communication, there is little understanding on how they transition to using these tools as a professional means of communication, or how these tools can be used to form a community of practice that fosters learning and engagement within Higher Education.

We invited 243 students at two Scottish universities to actively use Slack as the primary communication method across four modules of study, using a case study methodology. We used a pre-use and post-use questionnaire to evaluate students' attitudes and experience of using such a tool. This data, as well as their engagement with Slack, is used to create an understanding of how these tools were used over time within this case study. Finally, a number of recommendations are made on how these tools should be implemented within educational settings.

This is a timely addition to the literature in light of many institutions switching to online delivery of teaching materials due to the COVID-19 crisis [1].

Paper Contributions: We introduce three contributions: 1) Findings from an online questionnaire with 231 participants that reports on their use of online communication tools, which validate and extend anecdotal experiences of educators in relation to use of these tools both in education settings and more widely. 2) Teaching staff reflections on implementing a professional communication tool. 3) We collate our findings into recommendations for the inclusion of online messaging tools in Higher Education.

\section{LITERATURE REVIEW}

Social networks, and the communication tools embedded within, have a number of desirable qualities required for educational purposes [2]. For example, Facebook allows peer feedback in an environment that matches the social context of learning, e.g. school, university. There are a large number of examples of the use of social media in many forms within education [3], [4].

Further, students can actively participate in discussion by having the roles of both subject and partner in social interactions [5] and to communicate with other students outside of scheduled class time [2], and much learning may occur within this informal space [6]. There is growing evidence that points to an enhanced credibility of lecturers engaged in contemporary student culture [7] and familiarity though the use of social networks can make lecturers seems more approachable [8]. This can be a positive tool for breaking barriers between students and their mentors [9].

Over $95 \%$ of undergraduate students regularly use social networks [10], and this number is likely to have increased in recent years. While there has been some exploration of students' educational use of social networking sites [2], [5], there have been few empirical studies of the impact of social networks on pedagogy. 
The use of these communication tools allows for a continuation of informal discourse that typically would occur offline, with students focusing on using these technologies for informal rather than formal learning [11]. Previous studies on the use and integration of such tools in computing classrooms has shown that students"were enthusiastic about the benefits of informal communication with faculty" [12], leading to perceived benefits such as enabling better time management, fostering personal communication between students and faculty and within student groups, as well as giving a "realtime" feel to conversations as opposed to the asynchronous communication style afforded by traditional VLE fora [13], [14].

The use of communication tools such as Slack are a rising trend in the computing industry; particularly in streamlining communication between teams of developers: "we have found that Slack and its integration are playing an increasingly significant role in software development, replacing email in some cases and disrupting software development processes" [15].

Stray, Moe, and Noroozi [16] further show that whilst using social media as a communication platform leads to positive aspects such as increased transparency and informal communication, that there are a number of identified challenges, including "using too much direct messaging when communicating, and unbalanced activity". However, these issues may be mitigated against by setting and clarifying the expectation for any participant using these services as a communication tool [13].

It is clear that the use of communication tools can be beneficial to the formation of a professional community, which, in turn, can have a positive impact on a students' sense of belonging: "one straightforward way [to have a positive impact] is to incorporate social instruction strategies, like active and cooperative learning, in the classroom to help students connect with their peers who may provide feedback about a student's ability" [17]. In addition, such tools are frequently used in the workplace and so proficiency and skills in this area could boost employability.

However, little work has been conducted on specifically investigating the role of professional social networks and tools within education. In this paper, we present a case study of the use of Slack at two institutions in Scotland in order to explore how such these tools might be used within an education setting.

\section{CASE STUDY OVERVIEW}

Our case study took place over one semester at two universities in Scotland (12 and 14 weeks in length). Four modules, each worth 7.5-10 ECTS, were selected for inclusion in the study from within computing departments. All were taught by the authors and represented different types of learning experiences, e.g. includes both a smaller and larger class, and classes taken early and later in the degree programme. This allowed a variety of student demographics and experience to be represented in the study.
The aim of the case study was to improve communication within the student cohort, and to support the extensive groupwork elements that are included in teaching. A number of communication tools were considered for use, including Facebook and WhatsApp. We chose to focus on Slack ${ }^{1}$ due to its crossplatform connectivity, in-built analytics dashboard, and rising popularity across the industry. Further, Slack is a professional tool, unlike Facebook and WhatsApp, which are likely to be used on a personal basis, so would allow for a barrier to exist between a student's social life and their professional identity.

Ethical approval for the study was obtained by the Institutional Review Board at the University of Dundee. The authors have a combined 20 years of experience of teaching in Higher Education. Both authors have taught the modules included in this study for a number of years and so are familiar with the module content and any local administrative processes required.

An overview of the process used is outlined in Figure 1.

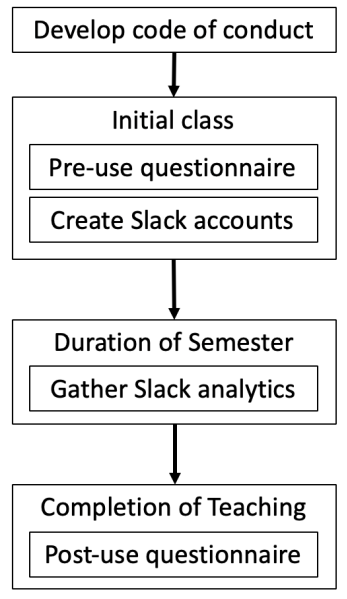

Fig. 1. Study process

\section{A. Code of Conduct}

Both researchers used previous have experience in using collaborative tools like Slack for small group-based projects, as well as recommendations provided by previous studies (e.g. [13]), to create a Code of Conduct document, which included guidelines for the use of Slack in the context of the module, expectations for student behaviour and conduct, and expectations for staff response time. Students who were involved in previous use of Slack, and student representatives for the relevant year groups across both institutions were asked to give feedback on the Code of Conduct before it was made available to the wider student body. The Code of Conduct ${ }^{2}$ was circulated to each student by email, and made available on the VLE for each of the participating modules.

\footnotetext{
${ }^{1}$ https://slack.com/

${ }^{2}$ https://tinyurl.com/sample-code-of-conduct
} 


\section{B. Initial Class for Each Module}

The first lecture for each participating module included a brief overview of the communication protocol for the module, introducing the VLE as the main repository for downloadable items and lecture overview, and Slack as the main conversation platform. Each of the students was sent a direct e-mail link to register for a Slack account.

\section{Use of Slack During the Semester}

Slack was not a prerequisite tool for the modules (due to institutional administration requirements), and communication could still be made with staff via traditional methods (i.e. e-mail, VLE). It was emphasised to the students that using Slack would provide students with a number of benefits, such as reduced waiting time for staff response, and access to a community of practice afforded by other students.

Each module consisted of a separate Slack workspace, with the following default channels accessible to all:

- \#general, for all-purpose discussion, with the following description: This channel is where you can ask questions of us and discuss things amongst yourselves. If you want to have private conversations within your team (and we encourage this!), you should create your own channels.

- \#random, for non work-related conversation.

Furthermore, the following private channel was created:

- \#staff, for discussion between members of academic staff and lab demonstrators allocated to the module.

Students were further encouraged to create their own channels if appropriate (e.g. for team-based modules), and to use the direct messaging facilities to get in contact with members of staff.

\section{Online Questionnaires}

We ran two online questionnaires with students: one during the first class and one on completion of the module. The aim of this was to address three research questions: 1) How do students currently communicate with others in relation to university study? 2) What opinions do students already have about Slack and other similar tools? 3) How successfully did students use Slack during the module?

\section{INSTITUTIONAL OVERVIEW}

Two institutions in Scotland were involved in this project: [uni1] and [uni2]. Each author is a faculty member at one of the institutions, with each author teaching two modules during one semester. In previous years, staff have attempted to foster online discussions through the use of a Virtual Learning Environment ([uni1] uses CampusMoodle, whilst [uni2] use Blackboard). Both VLEs have a discussion forum available to users, used to invite discussion, both for teaching purposes and to provide an online social space for students. However, this has not been successful. Navigating to the forum can be time consuming when compared to other online interactions, requiring a minimum of six clicks after logging into the VLE. This meant that students were reluctant to engage in the online discussions, and so interaction was minimal. Staff members were also unduly encumbered by the poor usability of the VLE and so were less inclined to promote such online discussion forums.

\section{A. Robert Gordon University}

Robert Gordon University is based in Aberdeen, Scotland and currently has 14,000 students and 1500 staff. In the School of Computing, there are approximately 500 students and 30 academic staff. The following modules were involved in this study:

- CM1107: Introduction to Computing for Digital Media. This is a first-year programming module taken by 18 undergraduate students, and the first point of contact these students have had with the institution. The module is examined through continuous assessment points across the semester, with students undertaking and submitting individual work.

- CM3108: Software Engineering and Project Management. This is a third-year project management team-based module taken by 106 undergraduate students. The module is examined through one major assessment point at the end of the semester, but the students are required to interact with a number of 'client meetings' in an agile manner.

\section{B. The University of Dundee}

The University of Dundee is based in Dundee, Scotland and currently has more than 17,000 students and 3000 staff in total. In Computing, there are approximately 350 students and 27 academic staff. The following modules were involved in this study:

- AC21011: Creative interactions. This is an introductory programming module taken by 117 undergraduate students (including both computing majors in first year and non-majors in second year). Classes include traditional lectures and practical sessions. The module is examined through group assignments and an end-of-semester multiple choice test.

- AC41012 and AC51010: User Experience. This is a cotaught fourth-year and Masters level module, taken by 19 students. Classes typically are facilitated group-based design activities, and assessment comprises group-based design work and a written examination.

\section{PRE-USE QUESTIONNAIRE}

The pre-use questionnaire was shared with students during the first session of each module. The students were advised that completion was optional and that there was no course credit for completion.

\section{A. Materials}

The online questionnaire comprised three main sections: 1) Demographics, including existing use of online messenger systems, 2) Attitudes towards the use of online messenger 
systems for education, and 3) Use of Slack for educational purposes.

The first section contained gathered demographic information: age, gender (we used an open text field [18]), nationality and whether they wished to declare any disabilities. In the pre-use questionnaire, we also determined how participants currently use online messenger systems. Participants were asked how often they use online messenger systems to communicate with others, what systems they use, what platforms (i.e. desktop, laptop, tablet, smartphone) they use to do so, and the main reasons that help them to decide what systems to use. Participants were asked to enter their student ID number, which was used to link their pre-use and post-use surveys.

The second section addressed participants' attitudes to the use of online messenger systems for education. Participants were asked how often they have used such tools to communication with peers, what applications they used and what platforms they used to do so. Similar to the general use section above, they were asked about the main reasons that help them to decide what systems to use.

The final section focused on the use of Slack for educational purposes. Participants were shown a video overview of Slack ${ }^{3}$. They were then asked if they had ever heard of Slack before, and whether they have ever used it. If the response was "Yes" then they were asked how often they have used it. Participants were asked to consider their expectation of Slack usage in relation to how useful it will be for their studies. They were also to evaluate how useful Slack will be for different purposes when compared with email and the VLE for different aspects of communication within their studies, e.g. to communicate with the lecturer or sharing ideas with peers. Finally, students were asked what features were most important to them when selecting a communication tool for their studies.

\section{B. Participants}

In total, 231 participants completed the pre-use questionnaire. Two participants were removed from our analysis due to not completing any questions. The remaining 229 participants $($ Male $=159$, Female $=70)$ were aged between 17-41 years old $(\mathrm{M}=21, \mathrm{SD}=3.76) .103$ participants were students at [uni1] and 126 were students at [uni2].

We asked participants if they had a disability. 12 participants responded "Prefer not to say", and 15 participants reported 19 disabilities: Dyslexia (9 participants), Autism Spectrum Condition (4), Dyspraxia (2), Diabetes (1), Visual stress (1), Learning disability (1) and Short-term working memory (1).

We asked how often participants used online messenger systems to communicate with others: "More than once per day" (188 participants), "At least once per day" (29), "At least once per week" (8) and "At least once per month" (2). Two participants did not respond.

We asked participants to list their top three communication applications that they use in general (i.e. not specifically for educational purposes): Facebook Messenger (200 participants), WhatsApp (138), Snapchat (114), Discord (73),

\footnotetext{
${ }^{3}$ https://www.youtube.com/watch?v=9RJZMSsH7-g
}

Instagram (52), iMessage (20), Slack (12), Twitter (10), Viber (9), Skype, Google Hangouts (6), Email (5), WeChat (4), Weibo, Steam (2), and Grindr, Kik, Line, mIRC, Pintrest, QQ, and Signal (1). Two primary reasons were identified as to why these systems were used: due to others using the tool (142 participants) and ease of use (70). Further responses were: speed of use (18), compartmentalising conversations (13), cross-platform compatibility (10), cost, security, aesthetics, accessibility (8), photo sharing, reliability (7), privacy (6), group chat (5), voice chat, no advertising, availability of backups (2) and using phone number, trust, notifications, tracking friends' locations, video calling, knowing when a message has been seen and professionalism (1).

\section{Results}

We asked participants about their attitudes to online messenger tools for education. Our participants used online messaging tools to communicate with others about their studies "more than once per day" (25 participants), "at least once per day" (99), "at least once per week" (78), and "at least once per month" (26). We further asked how often this occurred on different platforms.

We asked participants for top three communication applications: Facebook Messenger (202 participants), WhatsApp (93), Snapchat (83), Discord (58), Email (31), Instagram (29), iMessage (16), Slack (14), Microsoft Teams (11), VLE, Google Hangouts (4), Telegram, WeChat, Viber (3), Steam, Twitter, Skype (2), and QQ, mIRC, Weibo, Piazza, Trello, Box, and FaceTime (1). Two primary reasons were identified as to why these systems were used: others using the tool (113 participants) and ease of finding and adding people (41). Further responses were: ease of use (16), sending files (9), reliability, group conversations (8), user interface, sending large images (4), accessibility (3), security, cost, cross-platform compatibility, availability of backups (2), notifications and professionalism (1).

We asked participants if they had ever heard of Slack. 85 participants had and 144 had not. Three participants did not provide an answer. However, only 31 participants reported having previously used Slack. Of these participants, 30 indicated how often they used it: "more than once per day" (4 participants), "at least once per day" (2), "at least once per week" (10), and "at least once per month" (12).

Since the current technology infrastructure within both institutions consisted of a VLE and Email, we gave the participants a number of communication scenarios and asked them to identify whether they would use Email, VLE or Slack for that given communication. The results are shown in Table I. These results match our expectations of the use of Slack and mirror the details outlined in the Code of Conduct, which had not yet been seen by participants.

Finally, to determine the willingness of participants to embrace a learning curve on a new tool, we asked them to posit whether they would prefer "Using a communications tool that I already use or which is easy to learn and use, but which lacks many or most of the features that I find important" or "Using 
TABLE I

STUDENTS' EXPECTED USE OF COMMUNICATION TOOLS

\begin{tabular}{|l|c|c|c|}
\hline & Email & VLE & Slack \\
\hline $\begin{array}{l}\text { Communicating with my lecturer } \\
\text { about topics within the module }\end{array}$ & 134 & 13 & 78 \\
\hline $\begin{array}{l}\text { Communicating with my lecturer } \\
\text { about personal issues }\end{array}$ & 186 & 2 & 35 \\
\hline $\begin{array}{l}\text { Asking my peers about topics } \\
\text { within the module }\end{array}$ & 49 & 4 & 170 \\
\hline $\begin{array}{l}\text { Sharing my ideas about topics } \\
\text { within the module }\end{array}$ & 40 & 10 & 173 \\
\hline $\begin{array}{l}\text { Building relationships with } \\
\text { other students }\end{array}$ & 40 & 3 & 179 \\
\hline
\end{tabular}

a tool that has most or all of the features I find important, but which is not something I already use and would take effort to learn and use". 69 participants indicated that they would prefer using a tool that they already used, while 156 would be willing to learn to use a new tool. Four participants did not provide an answer.

\section{POST-USE QUESTIONNAIRE}

The post-use questionnaire was shared with students on completion of the module assessment, by advertising it on the VLE and on Slack, and by email communication. The students were again advised that completing the questionnaire was optional and that there was no course credit for completion.

\section{A. Materials}

1) Post-use: In the post-use questionnaire, participants were asked how often they had used different tools in the last semester (e.g. VLE, email, etc) and whether they used Slack. If the response was "No", participants were asked to provide a reason. If the response was "Yes" then participants were asked to provide a reason, the main features that they used and what features could be added. They were also asked whether they think Slack was useful for their studies and whether they would recommend it to others.

\section{B. Participants}

In total, 24 people completed the post-use questionnaire. One participant was removed from our analysis because they did not answer any questions. The remaining 23 participants $($ Male $=21$, Female $=2)$ were aged between 17-37 years old $(\mathrm{M}=23, \mathrm{SD}=5.38) .14$ participants were students at [uni1] and 10 were students at [uni2]. We asked our participants if they had a disability. One responded "Prefer not to say", and one reported having dyslexia.

\section{Results}

We asked participants about their attitudes to the use of Slack for educational purposes. 21 participants reported using Slack over the previous semester. Two did not use Slack. Reasons given for not using Slack included: a preference for Facebook Messenger and forgetting that Slack was an option.

Of those participants who did use Slack $(n=21)$, they used it due to it being a part of the module structure (9 participants), communicating with group members (7), communicating with the lecturer or entire class (3), communicating with an individual student (2), fitting with what others were using and when group members had no Facebook account (1). The participants used Slack primarily for communication within their group, and group work (13). Other responses included communicating with staff and the rest of the class (4), using Slack as an archive or repository for files (2), and to organise the use of alternative communication platforms (1).

Participants reported using the following features on Slack: the mobile application (20), participation in small-group discussions (18), receiving notifications on a mobile device (16), the web application (13), sending direct (private) messages to other students (12), the desktop application, receiving notifications on a laptop, making changes to notifications preferences, sending direct (private) messages to staff (9), integrating thirdparty plug-ins (8), and pushing notifications to an e-mail address (2).

The most useful feature reported was that all contacts (students and staff) were in the one place (e.g. "everyone in the class had it"). This meant that it was easy for students to find individuals who had been allocated to a group, e.g. by searching for their student ID in their email address. Other popular features were the ability to create channels and set different privacy levels, share files and code snippets, and the use of third-party plug-ins, e.g. gifs.

16 participants (76\% of those those who had used Slack) considered Slack to be useful for their studies. Three participants did not think it had been useful, commenting that they used Slack because "we had no choice", and so had limited engagement throughout the study, e.g. using it only to gather usernames for other tools in order to "move off Slack". Two participants replied "don't know".

13 participants (62\% of those who had used Slack) would encourage others to use Slack for educational purposes. Six participants would not, two replied "don't know".

\section{RECOMMENDATIONS}

We have identified a number of challenges that have influenced the use of Slack as a communication tool within an educational context. These relate to engagement of both staff and students within a social learning space. The following recommendations discuss how the adoption of an online communication tool should be managed within computing curricula in Higher Education in order to improve the rate of adoption and engagement by both staff and students. Given the prevalence of these tools within the software development industry, it is of particular importance that computing students have relevant educational experiences in order to equip them as competent professionals.

1) Empower Staff: Staff engagement is critical to the success of technology adoption in Higher Education, and so staff should be empowered to use new technologies through support and training. Early adoptors [19] should be ambassadors of these new technologies in order to ensure that teaching staff know how to use them and that there is support available as they expand their use of different features. With the rise 
of flexible working arrangements [20], it is important that staff are empowered to use any new technology in a flexible manner with respect to work-life balance and their own work timetable.

2) Embed New Technology in Institutional Infrastructure: Embedding new technology within an existing infrastructure is key - i.e. use of a single logon to minimise cognitive load. In addition, ensuring that all members of an institution have access to a given tool, it ensures that users can be identified easily, e.g. by a student ID. In addition, in selecting new tools from an established suite of tools, academic staff can use their own knowledge and competency [21] to select the most appropriate applications for their learning topics and learning environment.

3) Provide Clear Communication Guidelines: Communication guidelines, such as a Code of Conduct should be implemented and enforced. It is important that all users are aware of this, and that it is written in clear and easy to understand language [13]. It should be emphasised why a given tool has been selected, and how communication should be facilitated. This will support the development professional communication skills in students, which may increase their employment prospects in the future.

\section{DISCUSSION}

\section{A. Summary of Contributions}

1) Questionnaire data on use of online communication tools from 231 participants: Our findings demonstrate that computing students use a variety of online messaging tools and that these are consistent between general use and for educational purposes. The most popular tools were social media applications. The most popular reasons for using these systems were that their communication partners were using them, and the ease of use of these systems, likely due to their familiarity as a result of extended use. Some students used applications for communication within their studies that have been specified in their institution, e.g. 'Microsoft Teams'.

2) Teaching staff reflections on implementing a professional communication tool: We present reflections by the authors and other staff members on the implementation and usage of Slack as a professional communication tool. We identify different types of engagement relating to different levels of privacy, e.g. direct messaging $\mathrm{v}$ whole-class communications, and highlight the importance of using such tools to foster a community of practice within small groups and the wider cohort.

3) Recommendations for the inclusion of online messaging tools in Higher Education: We introduce recommendations to improve the adoption of online messaging tools within Higher Education. These should be considered by all levels of operational and strategic layers of staffing, such as developers, educational technologists and local decision makers.

\section{B. Staff Reflections}

This section includes reflections from staff members involved in the project, including the authors. The major benefit of using Slack was the informal communication between staff and students which resulted out of the use of an instant messaging system; e.g. the use of GIFs, light-hearted conversation, discussion of experiences of new technologies. The authors posit that this informal method of communication helps students to engage with discussions both within and outside the classroom, and makes it more likely for students to engage with staff regarding personal issues.

Previous studies [12] show the importance of specifying expectations placed upon staff when introducing an informal open communication tool: "the involvement of staff should be clearly specified ... staff should be clear whether they expect to have any direct involvement in the group, e.g. will they answer questions, and at what time of the day?". The Code of Conduct set these expectations to the students at the beginning, and as such, no staff member reported being overwhelmed by direct messages. However, it is clear that direct messages to staff increased at set points in the semester; for example, when an assessment was released to the class and when the assessment was due.

Staff members used the notification settings within Slack to be notified of workspace activity during office hours. This allowed staff to be agile when responding to students: using Slack led to a reduction of time spent dealing with e-mails and typical administrative tasks associated with running a module. Furthermore, when student queries appeared on the \#general channel, this meant that other students could (and did) reply - this proved useful when students had common queries (e.g. debugging errors on a programming IDE). This led to evidence of learning and engagement with the content, and an improved community of practice. A secondary benefit of this is that staff can monitor these discussions, address misunderstandings and, if necessary, communicate with the class to resolve upcoming issues.

A number of factors can influence student engagement in using these types of tools, which in turn can have a negative impact on the creation of an engaged community of practice - for example, first year students were observed to be more hesitant in using Slack due to a perceived lack of confidence and fear of scrutiny from their peers on a public space. Students were observed to be most active when the modules introduced or contained elements of groupwork: in these cases, the workspace can acted as a springboard for students to create their own channels, using the communication platform within their groups and beyond the current module.

A number of lessons were learnt from the implementation of Slack as a communication tool, and should be noted for anyone considering the adoption of this technology in a similar fashion:

- Staff should familiarise themselves with the documentation on workspace settings, and manage these carefully to ensure that only students with approved e-mail addresses can join the workspaces. Putting these measures in place helps to create a safe environment for students to engage with the module content and further develop their learning. 
- Slack offers free workspaces, and whilst these were adequate for use in the context of this study, one of the four modules hit the message threshold (at the time of writing, this activates once 10,000 messages are sent [22]). This meant that older messages could not be viewed or searched for. Whilst upgrading to a paid package restores these messages, there may be short-term consequences on active students who suddenly lose access to their content until these messages are restored.

\section{Limitations}

This study was conducted at two universities in Scotland over a limited period of one semester, and so the results may not be fully generalisable to other cultural settings, although the participant group included international students. The post-use survey had small participant numbers $(n=24)$. On completion of the module, students are focused on exam revision, and there may be a self-selection bias for participants who were more engaged.

We were unable to obtain a gender balanced group, yet we had $29 \%$ female participants, which is considerably higher than the current proportion of female computing students in Scotland [23].

\section{Future Work}

This paper presents an understanding of the student experience of using online communication tools within an educational context. Further work will look to investigate the needs of staff members who adopt these tools, and aims to better understand the implications that such tools, and the "always on" burden these tools could have on mental well-being and work-life balance.

When no clear communication tool is specified by staff, students tend to find common ground by selecting the most commonly used social media tool across their group, regardless of whether it has the required functionality, and despite personal preference ("I will use the tool that others are using"). An analysis of student comments shows that the choice of communication platform is not a trivial one, and for some, it can blur the boundaries between personal and professional life. There is a further question to be asked: by not limiting the choice of communication platform, are we placing undue anxiety and stress upon our students?

\section{CONCLUSIONS}

Professional social media and related communication tools are a crucial aspect of employment as a computing professional. However, there is limited evidence of how students may use such tools within Higher Education settings. We conducted an online questionnaire with 229 students across two universities in Scotland to explore how their computing curricula use online messaging tools for their studies. We found that popular social media tools were most prevalent, with limited experience of more 'professional' tools, such as Slack. We conducted a case study of Slack use within four taught modules and reflect on the student and staff experience.
Participants raised many benefits of using such a tool, leading to a number of recommendations to support others in adopting such tools within Higher Education computing.

\section{ACKNOWLEDGEMENTS}

The authors would like to thank all the students who participated in the project, as well as the staff members who joined the various channels to provide ongoing support.

\section{REFERENCES}

[1] U. I. for LifeLong Learning, "Covid-19 educational disruption and response." [Online]. Available: https://uil.unesco.org/covid-19educational-disruption-and-response

[2] N. Selwyn, "Faceworking: exploring students' education-related use of facebook," Learning, media and technology, vol. 34, no. 2, pp. 157-174, 2009.

[3] V. Benson and S. Morgan, Cutting-Edge Technologies and Social Media Use in Higher Education. IGI Global, 2014.

[4] F. T. E. Cheston, Christine C. and M. S. Chilsolm, "Social media use in education," Academic Medicine, vol. 88, no. 6, pp. 893-901, 2013.

[5] N. B. Ellison, C. Steinfield, and C. Lampe, "The benefits of facebook "friends:" social capital and college students' use of online social network sites," Journal of computer-mediated communication, vol. 12, no. 4, pp. 1143-1168, 2007.

[6] S. Billett, "Critiquing workplace learning discourses: Participation and continuity at work," Studies in the Education of Adults, vol. 34, no. 1, pp. 56-67, 2002.

[7] M. K. Kabilan, N. Ahmad, and M. J. Z. Abidin, "Facebook: An online environment for learning of english in institutions of higher education?" The Internet and higher education, vol. 13, no. 4, pp. 179-187, 2010.

[8] J. P. Mazer, R. E. Murphy, and C. J. Simonds, "I'll see you on "facebook": The effects of computer-mediated teacher self-disclosure on student motivation, affective learning, and classroom climate," Communication education, vol. 56, no. 1, pp. 1-17, 2007.

[9] H. L. Schwartz, "Facebook: The new classroom commons," The Chronicle of Higher Education, vol. 56, no. 6, pp. B12-B13, 2009.

[10] I. Mori, "Student expectations survey," Coventry: Joint Information Systems Committee, 2007.

[11] C. Madge, J. Meek, J. Wellens, and T. Hooley, "Facebook, social integration and informal learning at university: 'it is more for socialising and talking to friends about work than for actually doing work', Learning, media and technology, vol. 34, no. 2, pp. 141-155, 2009.

[12] R. Menzies, K. Petrie, and M. Zarb, "A case study of facebook use: Outlining a multi-layer strategy for higher education," Education and Information Technologies, vol. 22, no. 1, pp. 39-53, 2017.

[13] A. Tuhkala and T. Kärkkäinen, "Using slack for computer-mediated communication to support higher education students' peer interactions during master's thesis seminar," Education and Information Technologies, vol. 23, no. 6, pp. 2379-2397, 2018.

[14] L. Fulton, "Slack in education: A case study of alternative communication for groupwork in graduate level online education," in Society for Information Technology \& Teacher Education International Conference. Association for the Advancement of Computing in Education (AACE), 2018, pp. 1458-1463.

[15] B. Lin, A. Zagalsky, M.-A. Storey, and A. Serebrenik, "Why developers are slacking off: Understanding how software teams use slack," in Proceedings of the 19th ACM Conference on Computer Supported Cooperative Work and Social Computing Companion, ser. CSCW '16 Companion. New York, NY, USA: Association for Computing Machinery, 2016, p. 333-336. [Online]. Available: https://doi.org/10.1145/2818052.2869117

[16] V. Stray, N. B. Moe, and M. Noroozi, "Slack me if you can! using enterprise social networking tools in virtual agile teams," in Proceedings of the 14th International Conference on Global Software Engineering, ser. ICGSE'19. IEEE Press, 2019, p. 101-111. [Online]. Available: https://doi.org/10.1109/ICGSE.2019.00031

[17] N. Veilleux, R. Bates, C. Allendoerfer, D. Jones, J. Crawford, and T. Floyd Smith, "The relationship between belonging and ability in computer science," in Proceeding of the 44th ACM Technical Symposium on Computer Science Education, ser. SIGCSE '13. New York, NY, USA: Association for Computing Machinery, 2013, p. 65-70. [Online]. Available: https://doi.org/10.1145/2445196.2445220 
[18] M. K. Scheuerman, "Hci guidelines for gender equality and inclusivity; updated 5/13/2019," 2019, accessed: 2019-20-09. [Online]. Available: https://www.morgan-klaus.com/sigchi-gender-guidelines

[19] G. A. Moore, Crossing the Chasm: Marketing and Selling Disruptive Products to Mainstream Customers. Harper Collins, 2002.

[20] Adecco, "Flexible working on the rise." [Online]. Available: https://www.adecco.co.uk/blog/entries/flexible-working-on-the-rise

[21] P. Reed, "Staff experience and attitudes towards technology enhanced learning initiatives in one faculty of health \& life sciences," Research in Learning Technology, vol. 22, Sep. 2014. [Online]. Available: https://journal.alt.ac.uk/index.php/rlt/article/view/1490

[22] Slack, "Message, file and app limits on the free version of slack." [Online]. Available: https://slack.com/intl/en-gb/help/articles/115002422943-Messagefile-and-app-limits-on-the-free-version-of-Slack

[23] H. Graham, V. Fuertes, V. Egdell, and R. Raeside, "Women in ict and digital technologies: An investigation of the barriers to women entering, staying, and progressing in the sector, and actions to ameliorate this - executive summary," Tech. Rep., 2016. [Online]. Available: http://researchrepository.napier.ac.uk/Output/408031 